Article

\title{
Quasi-Randomized Trial of Effects of Perioperative Oral Hygiene Instruction on Inpatients with Heart Diseases Using a Behavioral Six-Step Method
}

\author{
Chie Omori ${ }^{1,2,3}$, Daisuke Ekuni ${ }^{1, * \mathbb{D}}$, Yumiko Ohbayashi ${ }^{3}$, Minoru Miyake ${ }^{3}$ and \\ Manabu Morita ${ }^{1}$ \\ 1 Department of Preventive Dentistry, Okayama University graduate School of Medicine, Dentistry and \\ Pharmaceutical Sciences, Okayama 700-8558, Japan; pspc6q1h@s.okayama-u.ac.jp (C.O.); \\ mmorita@md.okayama-u.ac.jp (M.M.) \\ 2 Department of Oral Health Sciences, Baika Women's University, Ibaraki 567-8578, Japan \\ 3 Department of Oral and Maxillofacial Surgery, Kagawa University Hospital, Kagawa 761-0793, Japan; \\ yumiko@med.kagawa-u.ac.jp (Y.O.); dentmm@med.kagawa-u.ac.jp (M.M.) \\ * Correspondence: dekuni7@md.okayama-u.ac.jp; Tel.: +81-86-235-6712
}

Received: 1 October 2019; Accepted: 30 October 2019; Published: 1 November 2019

check for updates

\begin{abstract}
The assessor-blinded, parallel-design, quasi-randomized study (alternating allocation) aimed to determine the effects of the six-step method on postoperative numbers of oral bacteria, periodontal status, and atrial fibrillation (AF) among inpatients with heart diseases and periodontitis. Seventy inpatients who received preoperative periodontal treatment were quasi-randomly assigned to intervention and control groups at University Hospital. The intervention group received intensive oral hygiene instruction using a six-step method for 15 minutes per week and the control group received routine oral hygiene instruction. Significantly fewer oral bacteria were identified on the tongue at discharge compared with baseline in the intervention than the control group (ANCOVA) (large effect size, $p=0.02$ ). Changes in scores for self-efficacy, plaque scores, probed pocket depth, and bleeding on probing between baseline and discharge were significantly greater in the intervention, than in the control group $(p<0.05)$. The period of postoperative AF (days) was significantly shorter in the intervention, than in the control group $(p=0.019)$. In conclusion, oral hygiene instruction using the six-step method decreased the numbers of oral bacteria on the tongue and improved self-efficacy, oral health behaviors, oral hygiene status, periodontal status, and period of postoperative AF among inpatients with periodontitis and heart diseases.
\end{abstract}

Keywords: oral hygiene instruction; perioperative period; self-efficacy; six-step method

\section{Introduction}

Atrial fibrillation (AF) is associated with increased morbidity and mortality [1] and it remains the most common complication after cardiac surgery, affecting $20 \%-50 \%$ of patients [2-5]. AF is associated with other cardiovascular diseases and increasing evidence has shown links between AF and local as well as systemic inflammation, such as obesity and rheumatoid arthritis [6,7]. However, the risks associated with postoperative AF are not fully understood [8,9].

Periodontitis is an inflammatory disease of the supporting structures of the teeth. As periodontitis is a possible trigger of chronic inflammation, recent studies suggest a link between periodontitis and heart diseases [10-13]. Recent studies on animal models [14] and humans [15] have suggested an association between $\mathrm{AF}$ and periodontitis. Thus, reducing infection with oral bacteria and inflammation is very important for the management of both $\mathrm{AF}$ and periodontitis. 
Postoperative, professional oral hygiene care can reduce the number of oral bacteria on the tongue [16], the numbers of oropharyngeal bacteria [17], and complications such as pneumonia [18]. On the other hand, self-care as well as professional care are needed to improve postoperative oral hygiene status, which contributes to complications. Thus, effective oral hygiene instruction is desirable to improve self-care among inpatients.

The six-step method can be an effective oral hygiene instruction $[19,20]$. It is based on the self-efficacy theory (self-confidence that one can take action necessary to lead to a specific result) [21] and employs a behavioral science approach that consists of six steps [22]. In dentistry, the self-efficacy scale for self-care (SESS) was developed for dental outpatients to evaluate self-efficacy. High SESS was correlated with better oral hygiene and periodontal health $[19,23]$. The six-step method was more effective for enhancing self-efficacy and behavioral change in oral hygiene than traditional oral hygiene instruction alone in outpatients [20]. However, whether this method is actually effective among inpatients is unknown.

For inpatients, it is very important to improve oral hygiene status including that of the tongue. Previous studies showed that heavier tongue coating precipitation increased the pneumonia incidence rate [24] and prolonged hospitalization days [25]. Furthermore, oral bacteria on the tongue were associated with periodontal status and sub-gingival microbiome [26,27]. Thus, we focused on oral bacteria on the tongue. We postulated that the six-step method would improve self-efficacy and oral hygiene status, including tongue, and then contribute to periodontal status among inpatients with heart diseases. Therefore, the present study aimed to determine the postoperative effects of the six-step method on the numbers of oral bacteria on the tongue, periodontal status, and AF among inpatients with heart diseases.

\section{Materials and Methods}

\subsection{Design}

This assessor-blinded, parallel-design, single-center, quasi-randomized study (alternating allocation) of inpatients at Kagawa University Hospital, Japan, between June 2016 and July 2017 followed Consolidated Standards of Reporting Trials (CONSORT) guidelines and was approved by the Ethics Committee at the Medical Faculty of Kagawa University (No. 28-026). All enrolled inpatients provided written informed consent to participate in this study. Eligibility criteria did not change between before and after the trial, which was registered under Current Controlled Trials in UMIN-ICDR (UMIN000031047).

\subsection{Blinding}

Study personnel, including the periodontal examiners and the investigator responsible for the data analysis, were blinded to intervention assignments. The patients were not blinded.

\subsection{Sample Size Calculation}

Sample size was estimated assuming a $1.0 \times 107(\mathrm{SD}, 1.3 \times 107) \mathrm{cfu} / \mathrm{mL}$ or greater reduction in the numbers of oral bacteria on the tongue in the intervention compared with the control group [16]. Based on the data, we determined that 28 inpatients per group would be necessary to provide $80 \%$ power with an alpha of 0.05 in two-tailed and unpaired t-tests. Assuming an attrition rate of $18 \%$, the planned sample size was 70 participants (35 per group).

\subsection{Participants}

Participants were recruited between June 2016 and July 2017 at the Department of Cardiovascular Surgery, Kagawa University Hospital. The inclusion criteria were heart diseases and admission to hospital for surgery. Exclusion criteria included inappropriate status for the trials, such as failure of written informed consent to participate in the study at the Department of Dentistry, receiving 
periodontal treatment and using systemic antibiotics during the six months before the trial started [28] or not having any teeth.

\subsection{Intervention}

All patients received mechanical tooth cleaning, scaling without using local anesthetic, and removal of the tongue coating at the dental chair of the Dentistry by dental hygienists in a single visit before operation. After the preoperative treatment, the patients were quasi-randomly and alternately assigned to intervention and control groups (1:1) [29].

Patients in the intervention group received intensive oral hygiene instruction by the six-step method 15 minutes per week $[19,23]$. The six-step method comprised identification of the problem, establishment of commitment and confidence, increased awareness of behavior, development and implement of an action plan, evaluation of the plan, maintenance of change, and the prevention of relapse. This summarizes how to apply the self-efficacy theory in health education $[19,20,23,30]$.

The previous six-step method [20] was modified for perioperative inpatients as follows.

- $\quad$ STEP 1: Identification of the problem

Knowledge, belief, and barriers to self-care were clarified by a dental hygienist in interviews. The information was obtained using the following questions: (i) How many times do you brush your teeth?; (ii) Do you have regular dental check-ups?; (iii) Do you use interdental brushes?; (iv) Do you clean your tongue?; (v) Have you previously tried to change your oral hygiene behavior?; (vi) What stops you from changing your beliefs or what are your major barriers to change? We also disclosed dental plaque accumulation using Red Cote Liquid (Sunstar Americas Inc. Schaumburg, IL, USA) so that each patient could determine areas that they were not brushing appropriately. The patients thus identified their problems.

- STEP 2: Creation of commitment and confidence

The clinical interview and counseling were expanded. The patients learned the importance of maintaining good perioperative oral hygiene status. A dental hygienist encouraged the patients to confirm their intention and to promote motivation.

- STEP 3: Increase awareness of behavior

Patient awareness of their own behavior was increased through self-monitoring. A dental hygienist instructed the patients to maintain a diary regarding toothbrushing and the use of interdental brushes to monitor their accomplishments and identify barriers to changes in behavior.

- STEP 4: Development and implementation of an action plan

Short-term action plans established according to the principle of gradualism were based on the skill, behavior, and oral hygiene status of each patient. These plans were concrete, realistic, achievable, and included "brush teeth three times each day", "use interdental brushes daily", or "clean the tongue every day". Patients set goals that they could achieve by the time of the next interview.

- STEP 5: Evaluation of the plan

Whether or not the patient implemented the action plan was evaluated. Successful experiences were acknowledged and supported. When the plan succeeded, the success experience was acknowledged. The dental hygienist praised improvements in the oral hygiene status of the patients, even if quite small. Failure was attributed to failure of the plan, and a new achievable plan was established.

- STEP 6: Maintenance of change and prevention of relapse

Some inpatients had perioperative high-risk situations that resulted in relapse; for instance, postoperative poor physical status, a sink located far from their hospital bed, or limited range of hand 
movement due to intravenous drips. Thus, it was important for the dental hygienist to safeguard and reinforce the new behaviors to help and encourage the patients.

Patients in the control group received routine oral hygiene instruction for 15 minutes per week. The technical guidance [31] of brushing was main part of routine oral hygiene instruction in the control group. The dental hygienists instructed mainly the Bass method and how to use interdental brushes according to the patients' oral condition. The oral hygiene instruction was standardized and assessed among dental hygienists sharing information of each patient.

A typical content of instruction in each group is shown in the Table 1. Instructions were started in both groups from postoperative day (POD) 3. Dental hygienists provided routine postoperative oral hygiene care, mechanical tooth cleaning, and tongue coating removal to both groups. Dental hygienists checked the adherence of patients to interventions.

Table 1. Typical oral hygiene instruction in the control and intervention groups.

\begin{tabular}{|c|c|c|}
\hline & Control & Intervention \\
\hline Priority & Teaching skills & Counseling \\
\hline $\begin{array}{l}\text { Disclosing dental } \\
\text { plaque accumulation }\end{array}$ & + & + \\
\hline Technical guidance of brushing & Teaching how to use interdental brushes & Teaching how to use interdental brushes \\
\hline Six-step method & \multirow{3}{*}{-} & \multirow{3}{*}{$\begin{array}{l}\text { Asking the reason why a patient did not use } \\
\text { interdental brushes and getting the patient to identify } \\
\text { the problem }\end{array}$} \\
\hline STEP1: & & \\
\hline $\begin{array}{l}\text { Identification of the problem in } \\
\text { each patient }\end{array}$ & & \\
\hline STEP2: & \multirow{2}{*}{-} & \multirow[b]{2}{*}{ Counseling the patient to use interdental brushes } \\
\hline $\begin{array}{l}\text { Creation of commitment and } \\
\text { confidence }\end{array}$ & & \\
\hline STEP3: & \multirow{2}{*}{-} & \multirow{2}{*}{$\begin{array}{l}\text { Instructing the patients to maintain the use of } \\
\text { interdental brushes by self-monitoring }\end{array}$} \\
\hline Increase awareness of behavior & & \\
\hline STEP4: & \multirow{2}{*}{-} & \multirow{2}{*}{$\begin{array}{l}\text { Setting an achievable plan, "use interdental brushes } \\
\text { daily," for the patient }\end{array}$} \\
\hline $\begin{array}{l}\text { Development and implementation } \\
\text { of an action plan }\end{array}$ & & \\
\hline STEP5: & \multirow{2}{*}{-} & \multirow{2}{*}{$\begin{array}{l}\text { Praising improvements in the oral hygiene status } \\
\text { after the patient used interdental brushes daily }\end{array}$} \\
\hline Evaluation of the plan & & \\
\hline STEP6: & \multirow{2}{*}{-} & \multirow{2}{*}{$\begin{array}{l}\text { Reinforcing the daily use of interdental brushes and } \\
\text { encouraging the patient }\end{array}$} \\
\hline $\begin{array}{l}\text { Maintenance of change and } \\
\text { prevention of relapse }\end{array}$ & & \\
\hline
\end{tabular}

\subsection{Outcome Assessment}

The primary study outcome was a change in the numbers of oral bacteria on the tongue between baseline and discharge. The sampling at discharge was performed 1 week after the final postoperative care by the dental hygienists. Secondary outcomes included changes in oral hygiene status, periodontal parameters, tongue coating scores, self-efficacy scores, and the incidence of postoperative AF.

\subsection{Measurements of Oral Bacteria on the Tongue}

Dental hygienists collected coatings from the surface of the tongue at the middle of the dorsum linguae for oral bacteria counts using a cotton swab with gentle pressure according to the manufacturer's procedure $[16,23]$. The numbers of oral bacteria in the samples were immediately measured using a simple, portable bacterial counter (Panasonic Healthcare Co. Ltd., Tokyo, Japan) [32] and are presented as colony-forming units (cfu/mL). After the training, to assess the examiner agreement, the numbers of oral bacteria on the tongue were recorded at the same time in each volunteer on preliminary calibration. The errors of measurement were $<6.4 \%$. 


\subsection{Oral Examination}

O'Leary's Plaque Control Record (PCR) [33] was determined after staining with Red Cote Liquid (Sunstar) and recorded with respect to plaque location (mesial, distal, buccal, and lingual) relative to the gingival margin around each tooth. A total of 30 probed pocket depths (PPDs) were probed at mesio-buccal, mid-buccal, disto-buccal, mesio-lingual, mid-lingual, and disto-lingual sits of all teeth using a CP-11 color-coded probe (Hu-Friedy Mfg. Co. LLC., Chicago, IL, USA) by two dental hygienists. Sites that bled upon gentle probing were recorded, and the proportions of sites with bleeding on probing (BOP) and the number of BOP-positive teeth were determined for each patient. For PPD, agreement to within $1 \mathrm{~mm}$ was $100 \%$ on preliminary calibration. Cohen's kappa-index was 0.88 . Periodontitis was diagnosed using panoramic X-rays according to the Japanese Society of Periodontology (2015) [34]. In brief, a dentist diagnosed periodontitis when clinical attachment loss or bone loss was evident [34]. Probed pocket depths or bone loss of $>6 \mathrm{~mm}$ or $>50 \%, 4-6 \mathrm{~mm}$ or $30 \%-50 \%$, and $<4 \mathrm{~mm}$ or $<30 \%$, respectively, were regarded as severe, moderate, and mild periodontitis [34], respectively if the patients had at least one site of the condition.

\subsection{Questionnaire}

Study personnel recorded medical histories, medications, and lifestyle information including alcohol consumption, smoking, toothbrushing frequency, and regularity of dental checkups. We also investigated personal self-efficacy based on scores on a self-efficacy scale for self-care (SESS) to confirm the effects of the six-step method [19,35].

\subsection{General Status of Patients}

Information about general and oral status was obtained from medical and dental records. Parameters were measured between the preoperative period and discharge. The extracted information included data about sex, age, body mass index (BMI), primary heart diseases (diseases of the circulatory system; International Statistical Classification of Diseases and Related Health Problems (ICD)-10), other diseases (ICD-10), medical history other than diseases of the circulatory system, type of surgery, surgical duration, duration of hospitalization, antibiotics, intubation, amount of bleeding during surgery, medications, number of days with fever $\geq 38.0^{\circ} \mathrm{C}$ during one week, blood findings, and incidences of postoperative complications.

\subsection{Statistical Analysis}

The unit of analysis was a patient. Data were statistically analyzed using SPSS software version 24.0 (Japan IBM Co., Tokyo, Japan). Primary and secondary variables were compared between the control and intervention groups using chi-square or t-tests. Outcomes between two groups were assessed using an analysis of covariance (ANCOVA) model that included surgical duration and type of surgery as covariates. Adjusted differences and $95 \%$ confidence intervals (CIs) were determined. Mean changes between the control and intervention groups determined by ANCOVA were compared using t-tests. Values with $p<0.05$ were considered significantly different, whereas in cases of periodontal status and tongue status, the test with Bonferroni correction to control the false discovery rate was used ( $p<0.05 / 4$ and $p<0.05 / 2$, respectively) [36].

The effect size was also assessed using Cohen's d (t-test) [37]. Effect size is an indicator of the meaningfulness of a change in a health status measure. The small, medium and large effect sizes are $\mathrm{d}$ $=0.20,0.50$ and 0.80 , respectively [37]. 


\section{Results}

\subsection{Participants Information at Baseline}

Figure 1 shows that among 78 screened individuals, 70 who were quasi-randomized between June 2016 and July 2017 completed the study (Figure 1).

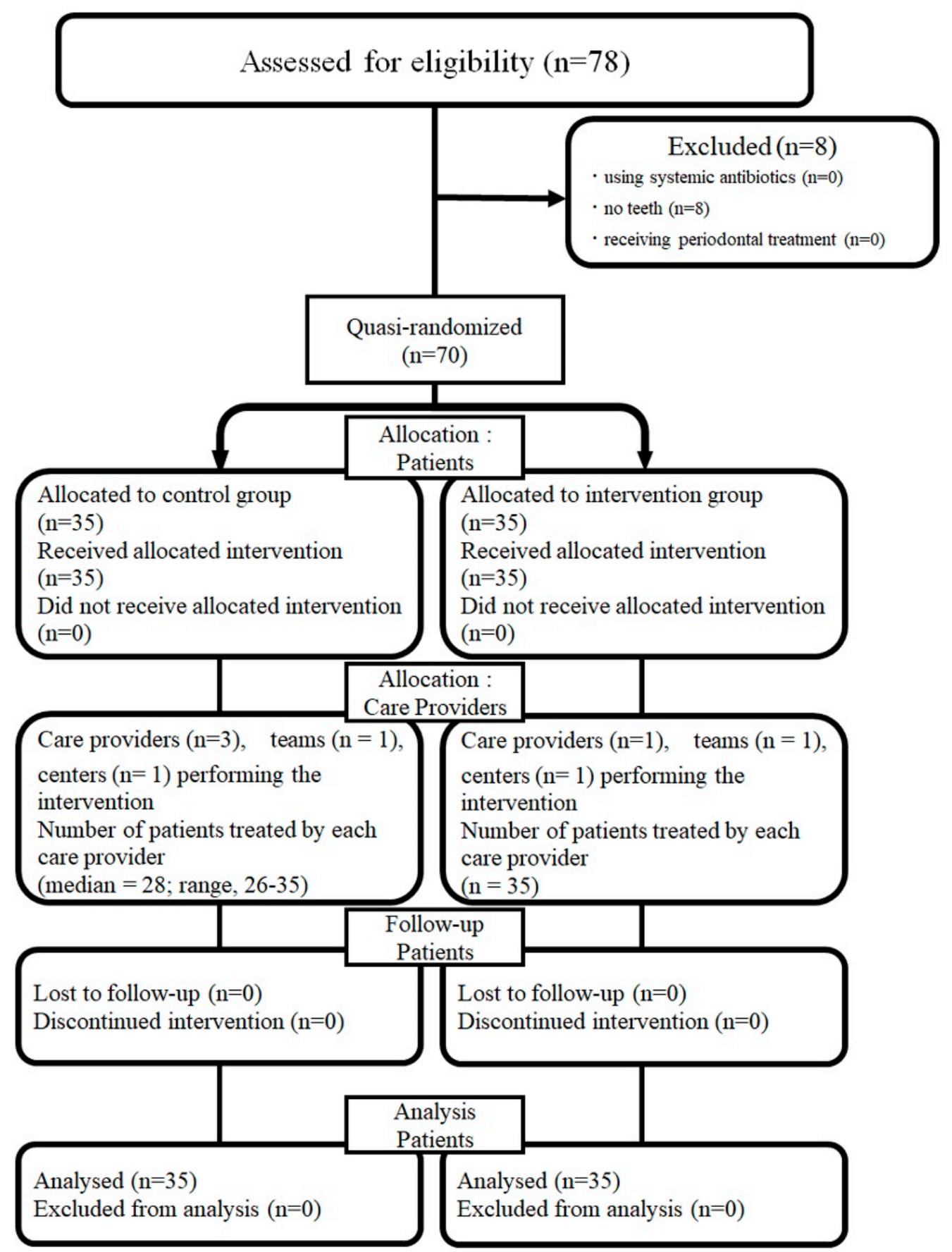

Figure 1. Flowchart of the study.

Table 2 shows that the baseline characteristics were similar between the control and intervention groups, and that none of them significantly differed $(p>0.05)$. Furthermore, oral health behavior [frequency of toothbrushing ( $\geq 2 /$ day), dental checkups (/year) and interdental brushing] at baseline 
was similar between the control and intervention groups [21 (60.0\%) vs. $21(60.0 \%), 1.1 \pm 3.0$ vs. $1.0 \pm 2.4,2(5.7 \%)$ vs. $3(8.6 \%)$, respectively], and none of them significantly differed $(p>0.05)$.

Table 2. Baseline characteristics of participants.

\begin{tabular}{|c|c|c|}
\hline Parameter & Control $(\mathrm{N}=35)$ & Intervention $(\mathrm{N}=35)$ \\
\hline Male & $24(68.6)^{*}$ & $24(68.6)$ \\
\hline Age (y) & $70.9 \pm 11.1$ & $68.1 \pm 11.4$ \\
\hline $\operatorname{BMI}\left(\mathrm{kg} / \mathrm{m}^{2}\right)$ & $22.0 \pm 4.1$ & $22.5 \pm 4.0$ \\
\hline \multicolumn{3}{|l|}{ Habit } \\
\hline Cigarette smoking & $26(74.3)$ & $23(65.7)$ \\
\hline Alcohol consumption & $13(37.1)$ & $15(42.9)$ \\
\hline \multicolumn{3}{|l|}{ Systemic conditions } \\
\hline \multicolumn{3}{|l|}{ Primary heart disease } \\
\hline Nonrheumatic mitral valve disorders & $7(20.0)$ & $9(25.7)$ \\
\hline Nonrheumatic aortic valve disorders & $5(14.3)$ & $7(20.0)$ \\
\hline Chronic ischemic heart disease & $6(17.1)$ & $6(17.1)$ \\
\hline Atherosclerosis & $8(22.9)$ & $4(11.4)$ \\
\hline Aortic aneurysm and dissection & $2(5.7)$ & $5(14.3)$ \\
\hline Angina pectoris & $3(8.6)$ & $2(5.7)$ \\
\hline Multiple valve diseases & $3(8.6)$ & $1(2.9)$ \\
\hline $\begin{array}{l}\text { Complications and vague descriptions of heart } \\
\text { disease }\end{array}$ & $1(2.9)$ & $0(0.0)$ \\
\hline $\begin{array}{l}\text { Infection following procedure, not elsewhere } \\
\text { classified }\end{array}$ & $0(0.0)$ & $1(2.9)$ \\
\hline Other heart diseases & $14(40.0)$ & $11(31.4)$ \\
\hline Medical history except for heart diseases (>2) & $12(34.3)$ & $11(31.4)$ \\
\hline Medications for heart diseases) $(>2)$ & $27(77.1)$ & $20(57.1)$ \\
\hline Medications for other diseases) (>2) & $20(57.1)$ & $18(51.4)$ \\
\hline \multicolumn{3}{|l|}{ Type of surgery } \\
\hline Aortic valve replacement & $11(31.4)$ & $6(17.1)$ \\
\hline Cardiac valve annuloplasty & $6(17.1)$ & $8(22.9)$ \\
\hline Vascular replacement & $2(5.71)$ & $8(22.9)$ \\
\hline Bypass & $16(45.7)$ & $12(34.3)$ \\
\hline Debridement & $0(0.0)$ & $1(2.9)$ \\
\hline \multicolumn{3}{|l|}{ Oral status } \\
\hline Number of teeth & $16.8 \pm 8.8$ & $19.4 \pm 8.8$ \\
\hline DMFT & $18.7 \pm 7.7$ & $17.9 \pm 7.8$ \\
\hline \multicolumn{3}{|l|}{ Periodontal status } \\
\hline Mean PPD (mm) & $4.5 \pm 1.0$ & $4.3 \pm 1.0$ \\
\hline $\mathrm{PPD} \geq 4 \mathrm{~mm}(\%)$ & $76.4 \pm 22.8$ & $69.3 \pm 23.6$ \\
\hline \multicolumn{3}{|l|}{ Periodontitis severity } \\
\hline Severe & $32(91.4)$ & $32(91.4)$ \\
\hline Moderate & $3(8.6)$ & $3(8.6)$ \\
\hline BOP $(\%)$ & $70.6 \pm 19.5$ & $63.7 \pm 21.2$ \\
\hline PCR $(\%)$ & $72.8 \pm 17.5$ & $73.3 \pm 17.6$ \\
\hline \multicolumn{3}{|l|}{ Tongue status } \\
\hline Tongue coating score & $1.1 \pm 0.9$ & $1.5 \pm 1.0$ \\
\hline Numbers of oral bacteria on tongue $\left(\times 10^{7} ; \mathrm{cfu} / \mathrm{mL}\right)$ & $3.8 \pm 2.8$ & $3.6 \pm 2.8$ \\
\hline SESS score & $55.5 \pm 13.3$ & $54.6 \pm 10.2$ \\
\hline
\end{tabular}

${ }^{*}$ Data are shown as means \pm SD or N (\%). BOP, bleeding on probing; DMFT, decayed missing and filled teeth; PCR, plaque control record; PPD, probed pocket depth; SESS, self-efficacy scale for self-care.

\subsection{Participants Status at Postoperative}

The numbers of postoperative oral hygiene care by dental hygienists were $4.5 \pm 1.5$ in the control group and $4.5 \pm 1.4$ in the intervention group. There was no significant difference in the number between the two groups $(p=0.806)$. Furthermore, there were no patients for whom self-care was difficult due to physical issues in the two groups. 
Table 3 shows differences in postoperative systemic conditions and oral health behaviors between the control and intervention groups. Surgical duration, the amount of bleeding during surgery, length of stay in hospital, intensive care unit (ICU), and coronary care unit (CCU), duration of intubation, and number of postoperative days to ingestion did not significantly differ. On the other hand, the period (days) of postoperative AF was significantly shorter in the intervention than in the control group $(p=0.019)$. Furthermore, oral health behavior [frequency of toothbrushing $(\geq 2 /$ day $)$ and interdental brushing] at discharge was improved compared to the baseline in the two groups and the number of patients who reported the use of interdental brushing in the intervention group was significantly larger than that in the control group. [33 (94.3\%) vs. $19(54.3 \%)](p<0.001)$.

Table 3. Differences in postoperative conditions between control and intervention groups.

\begin{tabular}{|c|c|c|c|}
\hline Parameter & $\begin{array}{l}\text { Control } \\
(\mathrm{N}=35)\end{array}$ & $\begin{array}{l}\text { Intervention } \\
(\mathrm{N}=35)\end{array}$ & $p^{\dagger}$ \\
\hline \multicolumn{4}{|l|}{ Surgical factors } \\
\hline Duration (min) & $344 \pm 162 *$ & $347 \pm 143$ & 0.934 \\
\hline Blood loss (mL) & $1208 \pm 1518$ & $1321 \pm 1584$ & 0.763 \\
\hline \multicolumn{4}{|l|}{ Duration of stays (days) } \\
\hline Hospital & $27.5 \pm 14.0$ & $29.5 \pm 14.2$ & 0.554 \\
\hline ICU & $3.4 \pm 3.3$ & $3.1 \pm 1.9$ & 0.569 \\
\hline CCU & $5.4 \pm 5.8$ & $3.6 \pm 2.4$ & 0.099 \\
\hline \multicolumn{4}{|l|}{ Medications } \\
\hline Postoperative medications (>2) & $33(94.3)$ & $30(85.7)$ & 0.615 \\
\hline Duration of antibiotics (days) & $5.7 \pm 7.2$ & $4.5 \pm 3.8$ & 0.386 \\
\hline Acetaminophen $\left(\times 10^{2} \mathrm{mg}\right)$ & $0.8 \pm 1.1$ & $0.8 \pm 1.3$ & 0.918 \\
\hline Flurbiprofen (mg) & $0.3 \pm 0.6$ & $0.1 \pm 0.4$ & 0.166 \\
\hline Fentanyl (mg) & $25.1 \pm 12.3$ & $28.7 \pm 11.4$ & 0.214 \\
\hline Remifentanil hydrochloride (mg) & $2.8 \pm 2.0$ & $3.5 \pm 2.0$ & 0.152 \\
\hline PCA $(\mathrm{mL})$ & $8.9 \pm 15.8$ & $8.5 \pm 13.3$ & 0.908 \\
\hline Intubation period (days) & $0.7 \pm 2.0$ & $0.5 \pm 1.5$ & 0.741 \\
\hline $\begin{array}{l}\text { Postoperative duration to ingestion } \\
\text { (days) }\end{array}$ & $2.1 \pm 3.4$ & $2.4 \pm 5.1$ & 0.804 \\
\hline $\begin{array}{l}\text { Number of days with fever } \geq 38.0^{\circ} \mathrm{C} \\
\text { within one week }\end{array}$ & $2.9 \pm 2.9$ & $2.1 \pm 2.0$ & 0.168 \\
\hline \multicolumn{4}{|l|}{ Blood test findings } \\
\hline CRP POD 1 (mg/dL) & $4.0 \pm 3.0$ & $3.8 \pm 2.3$ & 0.765 \\
\hline CRP POD 3 (mg/dL) & $11.1 \pm 6.8$ & $11.1 \pm 5.2$ & 0.995 \\
\hline CRP POD 7 (mg/dL) & $4.7 \pm 2.7$ & $4.7 \pm 3.5$ & 0.966 \\
\hline WBC POD $1\left(\times 10^{2} / \mu \mathrm{L}\right)$ & $94.1 \pm 28.3$ & $101.6 \pm 26.0$ & 0.248 \\
\hline WBC POD $3\left(\times 10^{2} / \mu \mathrm{L}\right)$ & $97.2 \pm 37.4$ & $142.4 \pm 248.1$ & 0.29 \\
\hline WBC POD $7\left(\times 10^{2} / \mu \mathrm{L}\right)$ & $77.6 \pm 26.7$ & $79.7 \pm 23.4$ & 0.716 \\
\hline \multicolumn{4}{|l|}{ Events } \\
\hline Atelectasis & $23(65.7)^{+}$ & $17(48.6)$ & 0.147 \\
\hline Postoperative pain & $26(74.3)$ & $26(74.3)$ & 1 \\
\hline Pneumonia & $4(11.4)$ & $1(2.9)$ & 0.164 \\
\hline Postoperative infection & $6(17.1)$ & $4(11.4)$ & 0.495 \\
\hline Delirium & $3(8.6)$ & $1(2.9)$ & 0.303 \\
\hline $\mathrm{AF}$ (day) & $4.8 \pm 7.6$ & $1.5 \pm 2.8$ & 0.019 \\
\hline AF incidence $(\%)$ & $19(54.3)$ & $12(34.3)$ & 0.092 \\
\hline Readmission & $7(20.0)$ & $5(14.3)$ & 0.526 \\
\hline
\end{tabular}

* Data are shown as means $\pm \mathrm{SD}$ or $\mathrm{n}(\%) .{ }^{+}$Chi-squared or t-tests. AF, atrial fibrillation; $\mathrm{CCU}$, coronary care unit; CRP, C-reactive protein; ICU, intensive care unit; PCA, patient controlled analgesia; POD, postoperative day; WBC, white blood cell count.

Table 4 shows changes in the clinical parameters between the control and intervention groups. Significantly fewer oral bacteria were found on the tongue between baseline and discharge in the intervention, than the control group ( $p<0.001$; effect size was large). Decreases in the amount of 
tongue coating and PCR scores between baseline and two weeks after surgery and between baseline and discharge were significantly greater in the intervention, than the control group $(p<0.001$; effect size was large). The decreases in mean PPD ( $\mathrm{mm})$, PPD $\geq 4 \mathrm{~mm}(\%)$, and BOP (\%) between baseline and discharge were also significantly greater in the intervention, than in the control group $(p<0.05$; effect size was large except for mean PPD). Changes in SESS scores between baseline and discharge from hospital were more significant in the intervention, than in the control group $(p=0.001$; effect size was large). Postoperative AF (day) persisted for significantly less time in the intervention, than the control group after adjustment ( $p=0.019$; effect size was medium).

Table 4. Differences in oral status, self-efficacy scale for self-care and atrial fibrillation between control and intervention groups.

\begin{tabular}{|c|c|c|c|c|c|}
\hline Parameter & $\begin{array}{l}\text { Control } \\
(\mathrm{N}=35)\end{array}$ & $\begin{array}{l}\text { Intervention } \\
(\mathrm{N}=35)\end{array}$ & $\begin{array}{l}\text { Adjusted Difference }{ }^{\dagger} \\
(95 \% \text { CI })\end{array}$ & $p \ddagger$ & Effect Size ${ }^{\S}$ \\
\hline \multicolumn{6}{|c|}{ One week after baseline } \\
\hline PCR (\%) & $73.0 \pm 22.5^{*}$ & $50.7 \pm 19.4$ & $-19.6(-27.9$ to -11.3$)$ & $<0.001$ & 1.06 \\
\hline Tongue coating score & $1.4 \pm 1.0$ & $1.6 \pm 1.0$ & $-0.1(-0.7$ to 0.3$)$ & 0.434 & 0.2 \\
\hline $\begin{array}{l}\text { Numbers of oral } \\
\text { bacteria on tongue } \\
\left(\times 10^{7}\right)(\mathrm{cfu} / \mathrm{mL})\end{array}$ & $2.4 \pm 2.4$ & $2.0 \pm 1.7$ & $-0.3(-2.0$ to 1.3$)$ & 0.71 & 0.19 \\
\hline \multicolumn{6}{|c|}{ Two weeks after baseline } \\
\hline PCR (\%) & $63.5 \pm 24.9$ & $39.2 \pm 22.1$ & $-21.8(-31.0$ to -12.7$)$ & $<0.001$ & 1.03 \\
\hline Tongue coating score & $1.3 \pm 1.0$ & $0.7 \pm 0.9$ & $-1.1(-1.6$ to -0.5$)$ & $<0.001$ & 0.63 \\
\hline \multicolumn{6}{|l|}{ At discharge } \\
\hline Mean PPD (mm) & $4.1 \pm 0.9$ & $3.6 \pm 0.7$ & $-0.3(-0.5$ to -0.1$)$ & 0.005 & 0.62 \\
\hline $\mathrm{PPD} \geq 4 \mathrm{~mm}(\%)$ & $61.4 \pm 26.8$ & $39.4 \pm 26.7$ & $-14.4(-21.9$ to -6.9$)$ & $<0.001$ & 1.16 \\
\hline BOP (\%) & $47.1 \pm 22.6$ & $27.6 \pm 15.6$ & $-11.4(-19.0$ to -3.90$)$ & 0.004 & 1.00 \\
\hline PCR (\%) & $62.5 \pm 22.8$ & $28.7 \pm 16.9$ & $-31.2(-39.9$ to -22.6$)$ & $<0.001$ & 1.68 \\
\hline Tongue coating score & $1.1 \pm 1.0$ & $0.3 \pm 0.5$ & $-1.2(-1.7$ to -0.6$)$ & 0.001 & 1.01 \\
\hline $\begin{array}{l}\text { Numbers of oral } \\
\text { bacteria on tongue } \\
\left(\times 10^{7}\right)(\mathrm{cfu} / \mathrm{mL})\end{array}$ & $3.0 \pm 2.1$ & $1.1 \pm 0.9$ & $-1.7(-3.2$ to -0.3$)$ & 0.02 & 1.18 \\
\hline SESS scores & $52.7 \pm 9.9$ & $60.6 \pm 10.1$ & 8.7 (3.6 to 13.8$)$ & 0.001 & 0.99 \\
\hline AF (days) & $4.8 \pm 7.6$ & $1.5 \pm 2.5$ & $-3.5(-5.6$ to -0.6$)$ & 0.019 & 0.58 \\
\hline
\end{tabular}

${ }^{*}$ Means \pm SD. + Adjusted for surgical duration and type of surgery. ${ }^{\ddagger}$ Changes in parameters between control and intervention groups based on t-tests after ANCOVA. \& Cohen's d. The small, medium and large effect sizes are d $=0.20,0.50$ and 0.80 , respectively. AF, atrial fibrillation; BOP, bleeding on probing; CI, Confidence interval; PCR, plaque control record; PPD, probing pocket depth; SESS, self-efficacy scale for self-care.

The interventions in both groups were implemented according to the schedule. Oral hygiene instructions were of low risk, and no serious, study-related adverse events developed. None of the patients required generalized periodontal rescue therapy during the study. There were no patients who had a delay between randomization and the initiation of the intervention in both groups. Furthermore, outcomes did not change after the trial commenced.

\section{Discussion}

The intervention group had a significantly greater decrease from baseline in the numbers of oral bacteria on the tongue, scores of tongue coating, and PCR than the control group at discharge from hospital. Self-care as well as professional care is needed to improve oral hygiene. Behavioral science approaches such as the six-step method have been developed to improve self-efficacy, oral hygiene status, and periodontitis among dental outpatients $[19,20]$. To the best of our knowledge, this is the first study of the effects of the six-step method on the postoperative oral hygiene status of inpatients with 
periodontitis and heart diseases. These findings supported our hypothesis that the six-step method improves self-care and oral hygiene status among inpatients.

Periodontal parameters and self-efficacy improved more in the intervention, than the control group. The six-step method decreased \%BOP and PPD and increased self-efficacy scores in a previous study of outpatients with periodontitis [20]. The present findings were similar to these, suggesting that the six-step method can help inpatients and outpatients with periodontitis to improve periodontal status and self-efficacy.

Postoperative AF persisted for a significantly shorter period (days) in the intervention, than the control group. Postoperative AF remains the most common complication of cardiac surgery [2-4]. Previous studies have associated local and systemic inflammation with AF [6,7] and others have suggested an association between AF and periodontitis [14,15]. Therefore, improving local inflammation or periodontitis using the six-step method might help to decrease the incidence or persistence of postoperative AF. However, further studies are required to investigate the mechanism of this relationship.

The amount of time required for oral hygiene instruction using the six-step method (approximately $15 \mathrm{~min}$ ) was similar to that of routine oral hygiene instruction based on the guidelines of the Japanese insurance system. The two groups spent a similar amount of time in the ICU/CCU and hospital, and the six-step instructions may help to improve oral hygiene status and periodontal health without using extra time. However, few dental professionals work on inpatients during the perioperative period. Thus, instructions will require further modification to shorten hospital/ICU stays and resolve perioperative staff shortages.

The six-step method is a systematic means of helping patients make lifestyle changes $[19,20,22]$. It applies self-efficacy theory to educate patients based on the hypothesis that self-efficacy initially improves and subsequently causes behavioral change [38]. Self-efficacy significantly improved, and interdental brushing significantly increased in the intervention group. Therefore, the present results suggest that oral hygiene instruction enhanced self-efficacy and then promoted behavioral change in the intervention group. The concept was supported by our previous study [20].

The incidence of postoperative pneumonia was lower in the intervention, than the control group ( $2.9 \%$ vs. $11.4 \%)$, but the difference did not reach statistical significance. A previous review found that the incidence of postoperative pneumonia varied from $0.5 \%-28 \%$ [39]. Since medical workers at our hospital usually control pneumonia in postoperative patients, the incidence of pneumonia in the present control group was relatively low. Thus, we could not detect a significant difference between the groups because of the floor effect.

At baseline, mean PPD and \%BOP in this study were within the previously published ranges of patients with periodontitis and heart diseases (mean PPD and \%BOP, 2.2-4.2 mm and 38.4\%-92.49\%, respectively) [40-42]. On the other hand, in this study, PPD $\geq 4 \mathrm{~mm}(\%)$ was $72.9 \pm 23.3( \pm \mathrm{SD}) \%$ at baseline, which was higher than a previous study among patients with stable coronary artery disease $(64.6 \pm 7.5 \%)$ [43]. Although participant age, country, sample size, and study design differed between the present and other investigations, caution is warranted in regard to the generalizability of the results.

The incidence of postoperative AF was $44.3 \%$ among the participants in the present study. The reported incidence of postoperative AF was $20 \%-50 \%$ [2-4], and that in the present study was within that range.

This study had several limitations. Longer follow-up studies are required because only a relatively short perioperative period was investigated. The short period may also have influenced the treatment response, particularly with respect to PPD reduction. Second, we enrolled a small patient cohort at a single center (selection bias), which might limit the ability to extrapolate our findings to the general population of inpatients. Therefore, further large-scale studies are needed to confirm our findings. Third, we could not investigate clinical attachment level because we had the limited time in a routine work of treatment. Fourth, we used quasi-randomization instead of randomization. We selected this method because we wanted to equalize the number of two groups, which was of advantage compared 
to simple randomization in case of a small number of participants. Finally, we did not investigate periodontal pathogenic species that may affect the results.

\section{Conclusions}

In conclusion, oral hygiene instruction using the six-step method significantly improved the numbers of oral bacteria on the tongue, periodontal status, and period of postoperative AF among inpatients with periodontitis and heart diseases.

Author Contributions: Data curation, C.O.; Formal analysis, C.O.; Investigation, C.O.; Methodology, C.O. and D.E.; Project administration, D.E.; Supervision, D.E., Y.O., M.M. (Minoru Miyake) and M.M. (Manabu Morita); Writing-original draft, C.O.; Writing—review and editing, D.E., Y.O., M.M. (Minoru Miyake) and M.M. (Manabu Morita).

Funding: This research received no external funding.

Acknowledgments: The authors are grateful to Kyoko Takakuni and Ayako Yamashita (Department of Oral and Maxillofacial Surgery, Kagawa University Hospital, Kagawa, Japan) for their technical support.

Conflicts of Interest: The authors declare no conflict of interest.

\section{References}

1. Senoo, K.; Suzuki, S.; Otsuka, T.; Sagara, K.; Matsuno, S.; Kano, H.; Uejima, T.; Oikawa, Y.; Yajima, J.; Nagashima, K.; et al. Progression to the persistent form in asymptomatic paroxysmal atrial fibrillation. Circ. J. 2014, 78, 1121-1126. [CrossRef] [PubMed]

2. Habib, R.H.; Zacharias, A.; Schwann, T.A.; Riordan, C.J.; Durham, S.J.; Shah, A. Effects of obesity and small body size on operative and long-term outcomes of coronary artery bypass surgery: A propensity-matched analysis. Ann. Thorac. Surg. 2005, 79, 1976-1986. [CrossRef] [PubMed]

3. Nishi, H.; Sakaguchi, T.; Miyagawa, S.; Yoshikawa, Y.; Fukushima, S.; Saito, S.; Ueno, T.; Kuratani, T.; Sawa, Y. Atrial fibrillation occurring early after cardiovascular surgery: Impact of the surgical procedure. Surg. Today 2013, 43, 1134-1139. [CrossRef] [PubMed]

4. Gillinov, A.M.; Bagiella, E.; Moskowitz, A.J.; Raiten, J.M.; Groh, M.A.; Bowdish, M.E.; Ailawadi, G.; Kirkwood, K.A.; Perrault, L.P.; Parides, M.K.; et al. Rate control versus rhythm control for atrial fibrillation after cardiac surgery. N. Engl. J. Med. 2016, 374, 1911-1921. [CrossRef]

5. Hernandez, A.V.; Kaw, R.; Pasupuleti, V.; Bina, P.; Ioannidis, J.P.; Bueno, H.; Boersma, E.; Gillinov, M.; Cardiovascular Meta-Analyses Research Group. Association between obesity and postoperative atrial fibrillation in patients undergoing cardiac operations: A systematic review and meta-analysis. Ann. Thorac. Surg. 2013, 96, 1104-1116. [CrossRef] [PubMed]

6. Gami, A.S.; Hodge, D.O.; Herges, R.M.; Olson, E.J.; Nykodym, J.; Kara, T.; Somers, V.K. Obstructive sleep apnea, obesity, and the risk of incident atrial fibrillation. J. Am. Coll. Cardiol. 2007, 49, 565-571. [CrossRef]

7. Lazzerini, P.E.; Capecchi, P.L.; Laghi-Pasini, F. Systemic inflammation and arrhythmic risk: Lessons from rheumatoid arthritis. Eur. Heart J. 2017, 38, 1717-1727. [CrossRef]

8. $\quad$ Lloyd-Jones, D.M.; Wang, T.J.; Leip, E.P.; Larson, M.G.; Levy, D.; Vasan, R.S.; D'Agostino, R.B.; Massaro, J.M.; Beiser, A.; Wolf, P.A.; et al. Lifetime risk for development of AF: The Framingham Heart Study. Circulation 2004, 110, 1042-1046. [CrossRef]

9. Im, S.I.; Chun, K.J.; Park, S.J.; Park, K.M.; Kim, J.S.; On, Y.K. Long-term Prognosis of Paroxysmal AF and Predictors for Progression to Persistnt or Chronic AF in the Korean Population. J. Korean Med. Sci. 2015, 30, 895-902. [CrossRef]

10. Spahr, A.; Klein, E.; Khuseyinova, N.; Boeckh, C.; Muche, R.; Kunze, M.; Rothenbacher, D.; Pezeshki, G.; Hoffmeister, A.; Koenig, W. Periodontal infections and coronary heart disease: Role of periodontal bacteria and importance of total pathogen burden in the Coronary Event and Periodontal Disease (CORODONT) study. Arch. Intern. Med. 2006, 166, 554-559. [CrossRef]

11. Teeuw, W.J.; Slot, D.E.; Susanto, H.; Gerdes, V.E.; Abbas, F.; D’Aiuto, F.; Kastelein, J.J.; Loos, B.G. Treatment of periodontitis improves the atherosclerotic profile: A systematic review and meta-analysis. J. Clin. Periodontol. 2014, 41, 70-79. [CrossRef] [PubMed] 
12. Dietrich, T.; Sharma, P.; Walter, C.; Weston, P.; Beck, J. The epidemiological evidence behind the association between periodontitis and incident atherosclerotic cardiovascular disease. J. Clin. Periodontol. 2013, 84, 70-84. [CrossRef] [PubMed]

13. Kimura, K.; Takase, B. Significant association between periodontitis and cardiovascular risk. Circ. J. 2014, 78, 837-838. [CrossRef] [PubMed]

14. Yu, G.; Yu, Y.; Li, Y.N.; Shu, R. Effect of periodontitis on susceptibility to AF in an animal model. J. Electrocardiol. 2010, 43, 359-366. [CrossRef] [PubMed]

15. Im, S.I.; Heo, J.; Kim, B.J.; Cho, K.I.; Kim, H.S.; Heo, J.H.; Hwang, J.Y. Impact of periodontitis as representative of chronic inflammation on long-term clinical outcomes in patients with AF. Open Heart 2018, 5, e000708. [CrossRef]

16. Mizuno, H.; Mizutani, S.; Ekuni, D.; Tabata-Taniguti, A.; Maruyama, T.; Yokoi, Y.; Omori, C.; Shimizu, K.; Morimatsu, H.; Shirakawa, Y.; et al. New oral hygiene care regimen reduces postoperative oral bacteria count and number of days with elevated fever in ICU patients with esophageal cancer. J. Oral Sci. 2018, 60, 536-543. [CrossRef] [PubMed]

17. Ishikawa, A.; Yoneyama, T.; Hirota, K.; Miyake, Y.; Miyatake, K. Professional oral health care reduces the number of oropharyngeal bacteria. J. Dent. Res. 2008, 87, 594-598. [CrossRef]

18. Yoneyama, T.; Yoshida, M.; Ohrui, T.; Mukaiyama, H.; Okamoto, H.; Hoshiba, K.; Ihara, S.; Yanagisawa, S.; Ariumi, S.; Morita, T.; et al. Oral Care Working Group, Oral care reduces pneumonia in older patients in nursing homes. J. Am. Geriatr. Soc. 2002, 50, 430-433. [CrossRef]

19. Kakudate, N.; Morita, M.; Yamazaki, S.; Fukuhara, S.; Sugai, M.; Nagayama, M.; Kawanami, M.; Chiba, I. Association between self-efficacy and loss to follow-up in long-term periodontal treatment. J. Clin. Periodontol. 2010, 37, 276-282. [CrossRef]

20. Kakudate, N.; Morita, M.; Sugai, M.; Kawanami, M. Systematic congnitive behavioral approach for oral hygiene instruction: A short-term study. Patient Educ. Couns. 2009, 74, 191-196. [CrossRef]

21. Bundura, A. Self-Efficacy; Toward a Unifying Theory of Behavioral Change. Psychol. Rev. 1977, 84, 191-215. [CrossRef]

22. Farquhar, J.W. The American Way of Life Need NOT Be Hazardous to Your Health; Da Capo Press: New York, NY, USA, 1987; pp. 35-54.

23. Kakudate, N.; Morita, M.; Kawanami, M. Oral health care-specific self-efficacy assessment predicts patient completion of periodontal treatment: A pilot cohort study. J. Periodontol. 2008, 79, 1041-1047. [CrossRef] [PubMed]

24. Abe, S.; Ishihara, K.; Adachi, M.; Okuda, K. Tongue-coating as risk indicator for aspiration pneumonia in edentate elderly. Arch. Gerontol. Geriatr. 2008, 47, 267-275. [CrossRef] [PubMed]

25. Da Cruz, M.K.; Morais, T.M.; Trevisani, D.M. Clinical assessment of the oral cavity of patients hospitalized in an intensive care unit of an emergency hospital. Rev. Bras. Ter. Intensiva 2014, 26, 379-383. [CrossRef]

26. Van Winkelhoff, A.J.; Van der Velden, U.; Winkel, E.G.; de Graaff, J. Black-pigmented Bacteroides and motile organisms on oral mucosal surfaces in individuals with and without periodontal breakdown. J. Periodontal Res. 1986, 21, 434-439. [CrossRef]

27. Göhler, A.; Samietz, S.; Schmidt, C.O.; Kocher, T.; Steinmetz, I.; Holtfreter, B. Comparison of Oral Microbe Quantities from Tongue Samples and Subgingival Pockets. Int. J. Dent. 2018. [CrossRef]

28. Engebretson, S.P.; Hyman, L.G.; Michalowicz, B.S.; Schoenfeld, E.R.; Gelato, M.C.; Hou, W.; Seaquist, E.R.; Reddy, M.S.; Lewis, C.E.; Oates, T.W.; et al. The effect of nonsurgical periodontal therapy on hemoglobin A1c levels in persons with type 2 diabetes and chronic periodontitis: A randomized clinical trial. JAMA 2013, 310, 2523-2532. [CrossRef]

29. Dixon, M. Does healing benefit patients with chronic symptoms? A quasi-randomized trial in general practice. J. R. Soc. Med. 1998, 91, 183-188. [CrossRef]

30. Gretchen-Doorly, D.; Subotnik, K.L.; Kite, R.E.; Alarcon, E.; Nuechterlein, K.H. Development and evaluation of a health promotion group for individuals with severe psychiatric disabilities. Psychiatr. Rehabil. J. 2009, 33, 56-59. [CrossRef]

31. Chapple, I.L.; Van der Weijden, F.; Doerfer, C.; Herrera, D.; Shapira, L.; Polak, D.; Madianos, P.; Louropoulou, A.; Machtei, E.; Donos, N.; et al. Primary prevention of periodontitis: Managing gingivitis. J. Clin. Periodontol. 2015, 42 (Suppl. 16), 71-76. [CrossRef] 
32. Kikutani, T.; Tamura, F.; Tashiro, H.; Yoshida, M.; Konishi, K.; Hamada, R. Relationship between oral bacteria count and pneumonia onset in elderly nursing home residents. Geriatr. Gerontol. Int. 2015, 15, 417-421. [CrossRef] [PubMed]

33. O'Leary, T.J.; Drake, R.B.; Naylor, J.E. The plaque control record. J. Periodontol. 1972, 43, 38. [CrossRef] [PubMed]

34. The Japanese Society of Periodontology. JSP Clinical Practice Guideline for the Periodontal Treatment; Ishiyaku Publishers, Inc.: Tokyo, Japan, 2015; pp. 24-28.

35. Mizutani, S.; Ekuni, D.; Furuta, M.; Tomofuji, T.; Irie, K.; Azuma, T.; Kojima, A.; Nagase, J.; Iwasaki, Y.; Morita, M. Effects of self-efficacy on oral health behaviours and gingival health in university students aged 18-or 19-years-old. J. Clin. Periodontol. 2012, 39, 844-849. [CrossRef] [PubMed]

36. Hochberg, Y.; Tamhane, A.C. Multiple Comparison Procedures (Wiley Series in Probability and Statistics); John Wiley \& Sons: Hoboken, NJ, USA, 1987.

37. Cohen, J. Statistical Power Analysis for the Behavioral Sciences, 2nd ed.; Lawrence Erlbaum Associates Publishers: Hillsdale, MI, USA, 1988.

38. Albright, C.L.; Farquhar, J.W. Principles of behavioral change. In Introduction to Clinical Medicine; Greene, H.M., Ed.; B.C. Decker, Inc.: Philadelphia, PA, USA, 1992; pp. 596-601.

39. Chughtai, M.; Gwam, C.U.; Mohamed, N.; Khlopas, A.; Newman, J.M.; Khan, R.; Nadhim, A.; Shaffiy, S.; Mont, M.A. The Epidemiology and Risk Factors for Postoperative Pneumonia. J. Clin. Med. Res. 2017, 9, 466-475. [CrossRef]

40. Karen, G.; Kaj, S.; Bjarne, S.; Finn, G.; Palle, H. Periodontal Disease and Coronary Heart Disease. J. Periodontol. 2006, 77, 1547-1554. [CrossRef]

41. Saffi, M.A.L.; Rabelo-Silva, E.R.; Polanczyk, C.A.; Furtado, M.V.; Montenegro, M.M.; Ribeiro, I.W.J.; Kampits, C.; Rösing, C.K.; Haas, A.N. Periodontal therapy and endothelial function in coronary artery disease: A randomized controlled trial. Oral Dis. 2018, 24, 1349-1357. [CrossRef]

42. Temelli, B.; Ay, Z.Y.; Aksoy, F.; Büyükbayram, H.İ.; Doğuç, D.K.; Uskun, E.; Varol, E. Platelet indices (mean platelet volume and platelet distribution width) have correlations with periodontal inflamed surface area in coronary artery disease patients: A pilot study. J. Periodontol. 2018, 89, 1203-1212. [CrossRef]

43. Montenegro, M.M.; Ribeiro, I.W.J.; Kampits, C.; Saffi, M.A.L.; Furtado, M.V.; Polanczyk, C.A.; Haas, A.N.; Rösing, C.K. Randomized controlled trial of the effect of periodontal treatment on cardiovascular risk biomarkers in patients with stable coronary artery disease: Preliminary findings of 3 months. J. Clin. Periodontol. 2019, 46, 321-331. [CrossRef]

(C) 2019 by the authors. Licensee MDPI, Basel, Switzerland. This article is an open access article distributed under the terms and conditions of the Creative Commons Attribution (CC BY) license (http://creativecommons.org/licenses/by/4.0/). 